\title{
PREVENCĊ̃o E CONTROLE DAS SEQÜELAS BUCAIS EM PACIENTES IRRADIADOS POR TUMORES DE CABEÇA E PESCOÇO*
}

\author{
Maria de Fátima Aparecida Cardoso ${ }^{1}$, Silviene Novikoff ${ }^{2}$, Adriana Tresso ${ }^{3}$, Roberto Araújo Segreto ${ }^{4}$, \\ Onivaldo Cervantes ${ }^{5}$
}

Resumo A cirurgia e a radioterapia são os principais métodos de tratamento das neoplasias de cabeça e pescoço. Dentre os efeitos colaterais resultantes da interação da radiação ionizante sobre os tecidos, temos dermatite, mucosite, xerostomia, candidíase, alteração do paladar, disfagia, cárie, trismo e osteorradionecrose. OBJETIVO: Avaliar a condição odontológica dos pacientes, através de protocolo que permita impedir ou minimizar os efeitos da radiação sobre os tecidos da cavidade bucal. MATERIAIS E MÉTODOS: Realizou-se acompanhamento odontológico, antes, durante e até 180 dias após a radioterapia, em 12 pacientes submetidos a cirurgia e radioterapia, ou radioterapia exclusiva. RESULTADOS: Efeitos como dermatite, mucosite, alteração do paladar e disfagia cresceram em proporção a partir da segunda semana de tratamento até o final das aplicações, decrescendo visivelmente quando do término, chegando próximos aos valores basais após 180 dias. Quanto à xerostomia, a redução ocorreu mais lentamente e com menor efetividade. Cárie, trismo e osteorradionecrose não foram observados durante o período de avaliação. CONCLUSÃO: 0 acompanhamento odontológico sistemático, junto com medidas preventivas como adequação bucal prévia, orientações sobre higienização, utilização de bochechos de água bicarbonatada, chá de camomila, aplicação tópica de flúor, contribuíram para promover melhores condições de restabelecimento em pacientes com neoplasia da região de cabeça e pescoço submetidos à radioterapia.

Unitermos: Seqüelas bucais; Odontologia; Radioterapia.

Abstract Prevention and control of sequels in the mouth of patients treated with radiation therapy for head and neck tumors.

Surgery and radiation therapy are de main treatments for head and neck cancer. The side effects of the interaction of ionizing radiation on the tissues include dermatitis, mucositis, xerostomia, candidiasis, dysgeusia, dysphagia, caries, trismus, osteoradionecrosis. OBJECTIVE: To assess dental condition of the patients using a protocol which allows avoiding or reducing the effects of radiation in the tissues of the oral cavity. MATERIALS AND METHODS: Dental follow-up was performed before, during and up to 180 days after radiation therapy in 12 patients submitted to surgery and radiation therapy or radiation therapy alone. RESULTS: The proportion of effects such as dermatitis, mucositis, dysgeusia, and dysphagia increased from the second week of the treatment until the end of the administrations. There was a clear decrease at the end of the treatment which was close to baseline values after 180 days. The reduction of xerostomia was slower and less effective. No case of caries, trismus, and osteoradionecrosis were observed during the assessment period. CONCLUSION: Regular dental follow-up associated with preventive measures such as prophylactic management of dental and oral diseases, adequate hygiene, mouth-washing with bicarbonate water and chamomile tea, and topic fluorine application contributed to improve the recovery conditions of patients with cancer of head and neck submitted to radiation therapy.

Key words: Oral sequels; Odontology; Radiotherapy.

\section{INTRODUÇÃO}

O câncer de cabeça e pescoço, que em nível mundial representa $10 \%$ dos tumores malignos, envolve vários sítios, sendo que cerca de $40 \%$ dos casos ocorrem na cavidade oral, $25 \%$ na laringe, $15 \%$ na fa-

* Trabalho realizado na Universidade Federal de São Paulo/ Escola Paulista de Medicina (Unifesp/EPM), Setor de Odontologia, Disciplina de Otorrinolaringologia, São Paulo, SP.

1. Cirurgiã-dentista, Mestre em Ciências Otorrinolaringológicas pela Unifesp/EPM.

2. Cirurgiã-dentista, Mestre em Ciências pela Unifesp/EPM.

3. Fisioterapeuta, Mestre em Ciências pela Unifesp/EPM.

4. Professor Adjunto, Livre-Docente do Setor de Radioterapia do Departamento de Medicina da Unifesp/EPM. ringe, $7 \%$ nas glândulas salivares e 13\% nos demais locais. Anualmente ocorrem mais de oito milhões de casos novos de câncer no mundo, dos quais 212.000 originam-se na boca ${ }^{(\mathbf{1})}$. No Brasil, o Instituto Nacional de Câncer estimou, para o ano de 2002, a ocorrência de 337.535 casos no-

5. Professor Livre-Docente da Disciplina de Cirurgia de Cabeça e Pescoço do Departamento de Otorrinolaringologia e Cirurgia de Cabeça e Pescoço da Unifesp/EPM.

Endereço para correspondência: Maria de Fátima Aparecida Cardoso. Setor de Odontologia, Disciplina de Otorrinolaringologia, Unifesp/EPM. Rua Botucatu, 740, Vila Clementino. São Paulo, SP, 04023-900. E-mail: cardosofa.compaq@uol.com.br Recebido para publicação em 26/11/2003. Aceito, após revisão, em 24/5/2004. vos de câncer, dos quais 11.255 de boca (3,3\%). Em nosso país, o câncer representa a terceira principal causa de morte ${ }^{(2)}$.

A cirurgia e a radioterapia (RT) continuam sendo os principais e mais eficazes métodos de tratamento dos tumores de cabeça e pescoço. A quimioterapia (QT) e a imunoterapia têm suas importâncias como terapias adjuvantes ${ }^{(1,3,4)}$.

A odontologia desempenha hoje um papel importante nas diferentes fases terapêuticas contra o câncer, seja na fase que antecede a cirurgia, em que uma avaliação prévia poderá reduzir de forma efetiva 
complicações oriundas de processos infecciosos ou inflamatórios crônicos, de origem bucal, que podem exacerbar após o tratamento cirúrgico, seja na prevenção das seqüelas bucais que ocorrem durante e após o tratamento por $\mathrm{RT}^{(5-9)}$.

A RT em câncer de cabeça e pescoço tem sua aplicabilidade e eficácia em função de parâmetros como tipo histológico da neoplasia (tecido de resposta lenta $\times$ tecido de resposta rápida), do local e do volume da área a ser irradiada, dose, ritmo de aplicação, tipo de radiação e condições gerais do paciente ${ }^{(\mathbf{1 0 - 1 2})}$.

A atuação do cirurgião-dentista se faz necessária em todas as fases da RT, pois haverá alterações, por efeitos colaterais da RT, nos tecidos moles e duros da boca e áreas adjacentes, resultado da interação da radiação ionizante com o tecido. Seu surgimento está associado à dose aplicada e ao tipo de radiação, bem como às características das células do tecido envolvido. Os principais efeitos são: dermatite, mucosite, xerostomia, perda do paladar, disfagia, trismo, cárie e osteorradionecrose, que ainda podem ser divididos em precoces e tardios, reversíveis e irreversíveis ${ }^{(\mathbf{5 , 1 2}-15)}$.

A necessidade, cada vez mais crescente, de atendimento a pacientes com neoplasias da região de cabeça e pescoço, que receberão RT exclusiva, ou após a cirurgia, nos estimulou à instituição de um protocolo visando à prevenção e controle das seqüelas bucais oriundas deste tratamento.

O nosso objetivo é avaliar a condição odontológica dos pacientes atendidos no setor de Cirurgia de Cabeça e Pescoço submetidos a cirurgia associada à RT ou a RT exclusiva, através de um protocolo que nos faculte visualizar as possíveis alterações nas diversas fases do tratamento, para, mediante orientação e/ou tratamento, prevenir, diagnosticar e controlar lesões do complexo maxilo-mandibular resultantes dos procedimentos cirúrgico e radioterápico.

\section{MATERIAIS E MÉTODOS}

Foram avaliados 42 pacientes, de ambos os sexos, com idade entre 37 e 70 anos, com média de 54,2 anos, portadores de neoplasias malignas de cabeça e pescoço, acompanhados no Serviço de Cirurgia de Cabeça e Pescoço da Disciplina de Otor- rinolaringologia da Universidade Federal de São Paulo/Escola Paulista de Medicina (Unifesp/EPM), submetidos a RT, com dose fracionada de 180 a 200 cGy/dia, com dose total entre 5.040 cGy e 7.000 cGy, em função do estádio do tumor, como complementar ou exclusiva, através de telecobaltoterapia. As doses foram prescritas após planejamento específico para cada paciente, cujo campo de irradiação envolvia a cavidade bucal e/ou complexo maxilomandibular. Do total de 42 pacientes, 12 foram acompanhados para a elaboração do nosso estudo, tendo como critério de elegibilidade o cumprimento total das etapas propostas: tratamento odontológico antes do início da RT, acompanhamento semanal durante o transcorrer da RT e acompanhamento de no mínimo seis meses após seu término. O não cumprimento de uma das etapas propostas foi o critério de exclusão.

O estudo foi analisado e aprovado pelo Comitê de Ética e Pesquisa da Unifesp/ Hospital São Paulo, sob o no 934/01.

\section{Avaliação da condição bucal}

Foi avaliada a condição bucal dos pacientes em três períodos distintos: antes, durante e após o procedimento radioterápico, num total de aproximadamente 250 dias. Estabeleceu-se um protocolo de aquisição dos dados visando ao acompanhamento de cada paciente, desde o seu encaminhamento ao ambulatório de odontologia até seis meses após o término da RT.

\section{Período que antecede a RT}

Realizaram-se, seguindo a orientação da ficha protocolar, anamnese, exame loco-regional e tomada de registro dental em um odontograma 1, no qual foram observados o número de elementos dentais presentes e o número dos ausentes. Quanto aos presentes, identificaram-se os que possuíam cárie, os que necessitavam de tratamento endodôntico, quando possuidores de cáries extensas, onde houvesse comprometimento pulpar, e os que tinham indicação de exérese, por estarem acometidos por cáries extensas, possuírem lesões periapicais, presença de fístulas, raízes residuais, ou ainda, mobilidade acentuada. Foram também observadas e anotadas as alterações gengivais e periodontais; quan- do necessário, exames complementares foram efetuados. O tempo de tratamento préRT foi o mais breve possível, em média três semanas.

Iniciamos o tratamento odontológico com uma exposição da importância da saúde bucal, no contexto geral de saúde, não só durante o período da RT, mas também no seguimento do tratamento. Em seguida, foi prescrito bochecho de solução de gluconato de clorexidina $0,2 \%$, três vezes ao dia até o início da RT, quando foi substituída por outras soluções. Ao mesmo tempo, orientações gerais de higienização foram demonstradas, como técnica de escovação - com modelos de arcada superior e inferior — , uso adequado do fio dental, remoção dos excessos alimentares na região de rebordo, palato e língua em pacientes edêntulos, com gaze embebida em solução fisiológica, limpeza de próteses parciais removíveis ou totais, para que fossem incorporadas à rotina dos pacientes.

A partir dessa adequação bucal inicial passamos para os procedimentos cirúrgicos. As exéreses foram realizadas, com antecedência mínima de 15 dias, com rigor de técnica, visando ao menor trauma na estrutura óssea que envolve o elemento dental, bem como no tecido gengival, que deverá ser coaptado de forma a permitir uma reparação mais rápida e segura.

Concomitantemente, realizamos a remoção dos cálculos salivares supra e subgengivais através de raspagem coronária e polimento radicular. Após este procedimento, realizou-se a aplicação tópica de flúor gel neutro, que possibilita a diminuição da sensibilidade da área tratada.

Por fim, realizou-se o tratamento dos elementos dentais com cáries, em que se procedeu à remoção do tecido cariado, limpeza da cavidade com solução de clorexidina $2 \%$ (clorexidina $2 \%-\mathrm{FGM}^{\circledR}$ ), isolamento relativo com rolete de algodão, preenchimento da cavidade com ionômero de vidro (Ionofil ${ }^{\circledR}$ - Voco, Alemanha) e polimento. Nessa fase elegemos também realizar a troca de restaurações que estavam com as bordas irregulares ou que, porventura, poderiam vir a apresentar problemas no desenrolar do tratamento.

Após terem sido realizados todos os procedimentos previstos, tomou-se um novo registro, o odontograma 2 . O paciente 
deveria estar apto, do ponto de vista odontológico, para iniciar a RT.

\section{Período durante a RT}

No decorrer desse período foram alvo de nossa observação semanal, para avaliação e controle, as possíveis alterações da cavidade bucal decorrentes da RT. Foram registrados, conforme referências descritas a seguir, o estado geral do paciente, dermatite, mucosite, xerostomia, candidíase, alteração do paladar, disfagia, cárie, trismo e osteorradionecrose.

Estado geral - Avaliado a cada visita do paciente e seu índice expresso através da escala de Karnofsky ${ }^{(\mathbf{1 6})}$.

Dermatite - Avaliada por meio de observação clínica, sendo considerado o aspecto da pele no local das aplicações, onde inicialmente nenhuma alteração é observada. Com a progressão das aplicações há o aparecimento de eritema, seguido ou não de descamação seca ou úmida, podendo evoluir até a ulceração, que quando presente, é necessária a interrupção da RT.

A dermatite foi classificada em ausente e presente; quando presente, foi subdividida em leve, moderada e grave: leve presença de eritema ou hipercromia; moderada - presença de descamação seca ou úmida; grave - descamação com ulceração (Figura 1).

Mucosite - Avaliada através de observação clínica, sendo considerado o aspecto da mucosa bucal. Classificada em graus de toxicidade, de 0 a 4 , de acordo com a intensidade, tomando-se como base a associação de critérios do National Cancer Institute (NCI-CTC) e da World Health Organization $(\mathrm{WHO})^{(\mathbf{1 7})}$ : $0=$ ausente $(\mathrm{mu}-$ cosa e gengiva estão úmidos e róseos); 1 = descoloração, aspecto esbranquiçado, possibilitando dieta normal; 2 = eritema, possibilitando dieta normal; 3 = pseudomembrana, requerendo dieta líquida (Figura 2); 4 = ulceração profunda, que impossibilitava a alimentação oral.

Xerostomia - Avaliada através de observação clínica e relato do paciente, que a cada sessão semanal expressava sua condição salivar, em relação à quantidade e qualidade, utilizando-se escala de 0 a 10 , em que o máximo (10) é fixado pelo observador, sendo considerado como valor basal, por haver outras condições, independentemente da RT, que podem estar alterando o item estudado. Quanto ao mínimo (0), traduzirá a condição de ausência total da saliva. Antes que a nota tivesse sido expressada, alguns questionamentos foram realizados:

- $\mathrm{O}(\mathrm{A})$ senhor(a) tem notado alguma diferença em sua saliva?

- O(A) senhor(a) considera essa(s) alteração(s) importante(s)?

- As alterações interferem de alguma forma na sua alimentação?

- As alterações interferem na sua fala?

- As alterações interferem no uso da sua prótese?

- As alterações interferem na sua qualidade de vida?
- Considerando o peso dessas alterações no seu dia-a-dia, qual nota daria para a sua condição salivar hoje?

Candidíase - Avaliada através de observação clínica, em que a presença de alterações brancas, amareladas, cremosas, removíveis à raspagem é indício de Candida, confirmada através da resposta da terapêutica antifúngica instituída, e classificada em ausente e presente.

Alteração do paladar - Avaliada através do relato do paciente ao ser indagado sobre a presença dessas alterações, por intermédio de questões:

- $\mathrm{O}(\mathrm{A})$ senhor(a) tem percebido modificações no sabor dos alimentos?

- $\mathrm{O}(\mathrm{A})$ senhor(a) pode distinguir salgado e doce?

A alteração do paladar foi classificada em ausente e presente, e quando presente, subdividida em leve, moderada e grave: leve - consegue distinguir salgado e doce; moderada - consegue distinguir um deles; grave - ausência total de paladar.

Disfagia - Avaliada através do relato do paciente ao ser questionado sobre a dificuldade de ingerir os alimentos:

- $\mathrm{O}$ (A) senhor(a) tem tido algum tipo de dificuldade para ingerir os alimentos?

- Qual o tipo de alimento (sólido/líquido/pastoso) cuja dificuldade torna-se mais acentuada?

A disfagia foi classificada em ausente e presente, e quando presente, subdividida em leve, moderada e grave: leve - consegue deglutir alimentos sólidos com dificul-

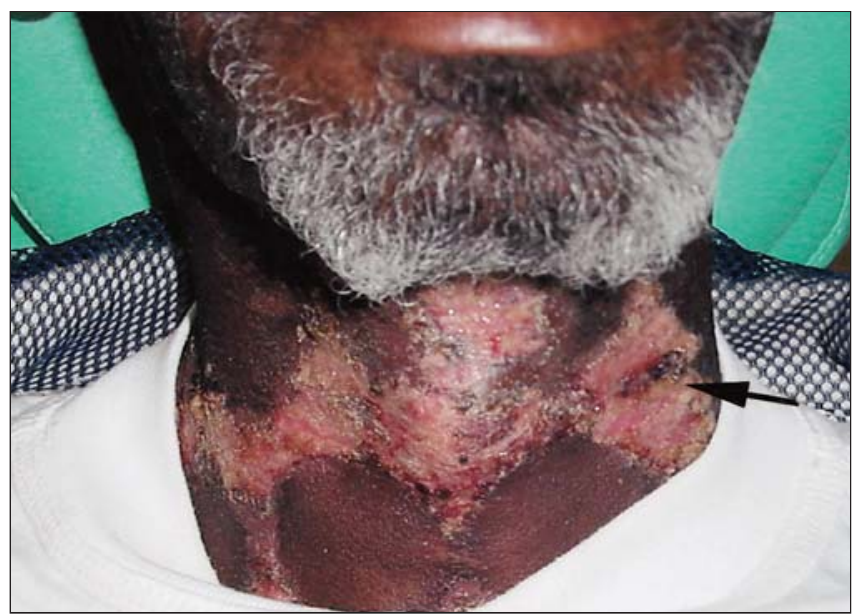

Figura 1. Presença de dermatite grave em paciente na vigência de RT.

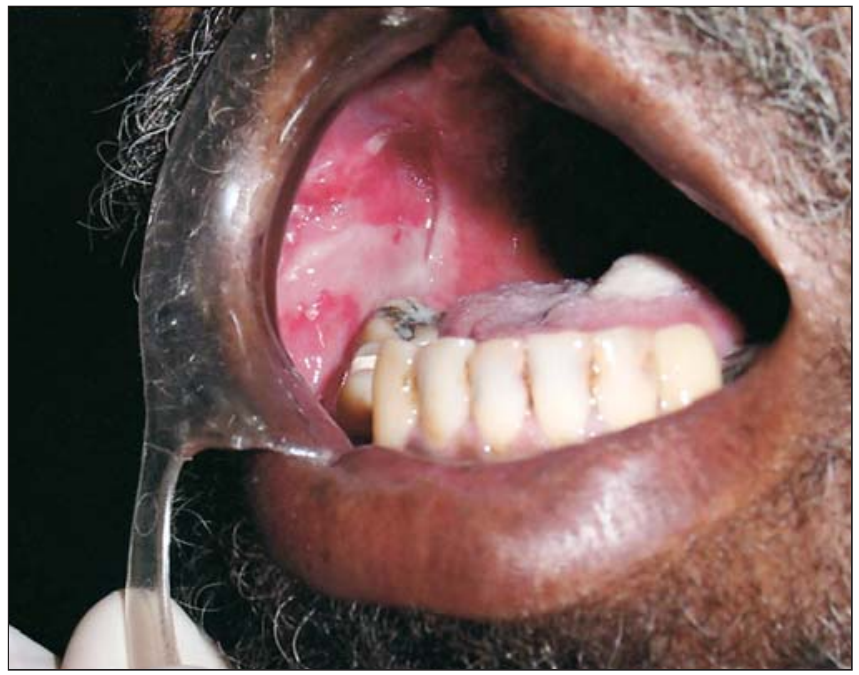

Figura 2. Mucosite oral em paciente durante a vigência da RT. 
dade; moderada - consegue deglutir alimentos pastosos e líquidos; grave - alimentação através de sonda.

Cárie - Avaliada por intermédio de observação clínica, com auxílio de sonda exploradora e espelho, em que toda a superfície dental externa é inspecionada, na procura de cavitação já instalada, ou ainda, de manchas brancas na superfície do esmalte, que podem indicar a evidência de que a desmineralização do esmalte esteja ocorrendo. O fio ou fita dental, passado pelas superfícies proximais, pode auxiliar na detecção. As radiografias periapicais constituem método auxiliar no diagnóstico. Quanto à ocorrência, foi classificada em ausente e presente.

Trismo - Avaliado através do relato do paciente, quando questionado sobre a dificuldade de abertura bucal. Medidas da abertura interincisal, com régua milimetrada, foram tomadas pelo observador no início e no final do tratamento.

- $\mathrm{O}$ (A) senhor(a) tem apresentado dificuldades para abrir a boca?

O trismo foi classificado, quanto à sua presença, em ausente e presente.

Osteorradionecrose - Diagnosticada ou não através de avaliação clínica e radiográfica (RX periapical e panorâmico), em que a presença de ulceração da mucosa com exposição óssea, associada a sintomas dolorosos, trismo e visualização radiográfica de áreas de reabsorção e neoformação — seqüestro ósseo, nos faculta o diagnóstico de osteorradionecrose.

No Quadro 1 estão descritos os procedimentos gerais aplicados a essa fase para todos os pacientes durante a RT.

\section{Período após a RT}

Com a conclusão da RT, os pacientes foram avaliados em intervalos crescentes, aos $7,15,30,60,90,120$ e 180 dias, considerando-se os mesmos aspectos abordados no período anterior e seguindo-se as mesmas referências. Os procedimentos gerais para esse período estão relacionados no Quadro 2.

\section{RESULTADOS}

Os resultados referentes a dermatite, candidíase, alteração do paladar e disfagia são apresentados nos gráficos representa-

Quadro 1 Procedimentos utilizados durante a RT.

1. Reforço das orientações sobre higienização.

2. Suspensão temporária do uso de prótese parcial removível e prótese total.

3. Suspensão do uso de solução de gluconato de clorexidina $0,2 \%$.

4. Introdução dos bochechos de água bicarbonatada - Uma colher de sobremesa de bicarbonato de sódio em um litro de água fervida e filtrada. Bochechar cinco vezes ao dia.

5. Introdução dos bochechos de chá de camomila - Duas colheres de sopa da erva seca em infusão em meio litro de água fervente, deixar esfriar. Bochechar cinco vezes ao dia, intercalando com o bochecho de água bicarbonatada.

6. Aplicação diária de flúor gel neutro em pacientes dentados, uma vez ao dia por quatro minutos.

7. Em presença de candidíase - Uso de nistatina suspensão,100.000 Ul/ml, para bochechos. Usar volume de $5 \mathrm{ml}$, que deve ser mantido na boca por três a cinco minutos antes de ser ingerido, três vezes ao dia por 14 dias. Durante o período que estiver fazendo uso da nistatina, a água bicarbonatada deverá ser substituída por bochechos de solução salina 0,9\%, e deverá ser reintroduzida assim que o tratamento apresentar resultado satisfatório.

8. Exercícios de abertura e fechamento de boca, dez vezes, para completar uma série; cinco séries três vezes ao dia, bem como relaxamento mandibular e massagens, com movimentos circulares na região da articulação temporomandibular.

Quadro 2 Procedimentos utilizados após a RT.

1. Reforço das orientações de higienização.

2. Manutenção da suspensão do uso da prótese parcial removível e prótese total por 180 dias.

3. Bochechos com água bicarbonatada por 30 dias, cinco vezes ao dia.

4. Bochechos com chá de camomila cinco a dez vezes ao dia, por 180 dias.

5. Em caso de candidíase, nistatina via oral.

6. Redução das aplicações de flúor gel neutro. A partir de 30 dias, passar para duas vezes por semana. Após 60 dias, uma vez por semana, e após 90 dias, uma vez ao mês.

7. Manutenção dos exercícios fisioterápicos por 180 dias.

8. Realização de RX panorâmico após 180 dias.

9. Liberação para uso de prótese parcial removível e prótese total, após 180 dias, e rigorosa observação quanto à adaptação delas em relação aos tecidos de suporte e oclusão.

dos pelas Figuras 4, 7, 8 e 9, construídos a partir de valores atribuídos à presença ou ausência dos parâmetros avaliados, onde:

Ausente: 0

Presente: Leve........... 1

Moderado... 2

Grave.......... 3

Para a mucosite a variação dos valores é de 0 a 4 (gráfico mostrado na Figura 5).

O gráfico da xerostomia (Figura 6) foi elaborado através de nota, e o gráfico do estado geral (Figura 3), pela porcentagem, seguindo a tabela Karnofsky. Quanto ao trismo, à cárie e à osteorradionecrose, não foram observadas alterações durante $o$ nosso período de avaliação.

\section{DISCUSSÃO}

A pele, sendo um tecido de resposta rápida, apresenta manifestações clínicas em curto período de tempo após a irradiação, entretanto, as células precursoras que escaparam da morte possuem grande capacidade de se dividir e repopular, mantendo, assim, a homeostase do tecido ${ }^{(11)}$.

Em nosso estudo a dermatite ocorreu em todos os pacientes, tendo sido observada a partir da segunda semana do início da RT; apenas um, entre os 12 pacientes, teve o tratamento interrompido, pelo período de uma semana, em decorrência do agravamento, que se iniciou por volta da terceira semana e se estendeu até o final das aplicações. Uma semana após a interrupção era possível observar melhora acentuada, permitindo que houvesse a continuidade do tratamento. Os demais pacientes tiveram pico de proporções moderadas entre a terceira e sétima semanas de tratamento, evoluindo para aumento de proporções leve e ausente após dois meses. Ao final de seis meses tivemos $75 \%$ de ausentes para $25 \%$ de leve, em que a principal característica observada foi a hipercromia no local irradiado. 


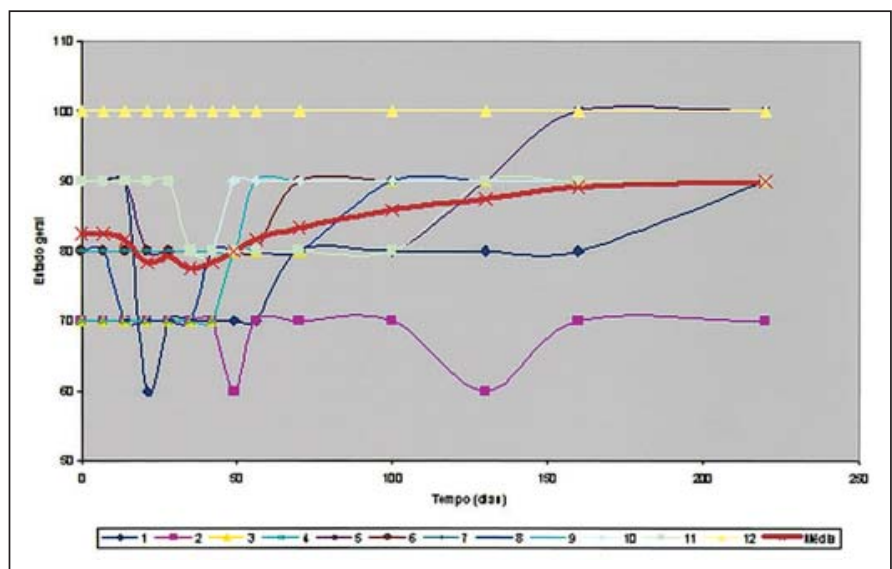

Figura 3. Representação gráfica do estado geral em função do tempo, em uma série de 12 pacientes com neoplasia na região de cabeça e pescoço que receberam RT. ( $\mathrm{T}=0$ : início da RT; t = 49: término da RT; t > 49: início do acompanhamento após o término da RT).

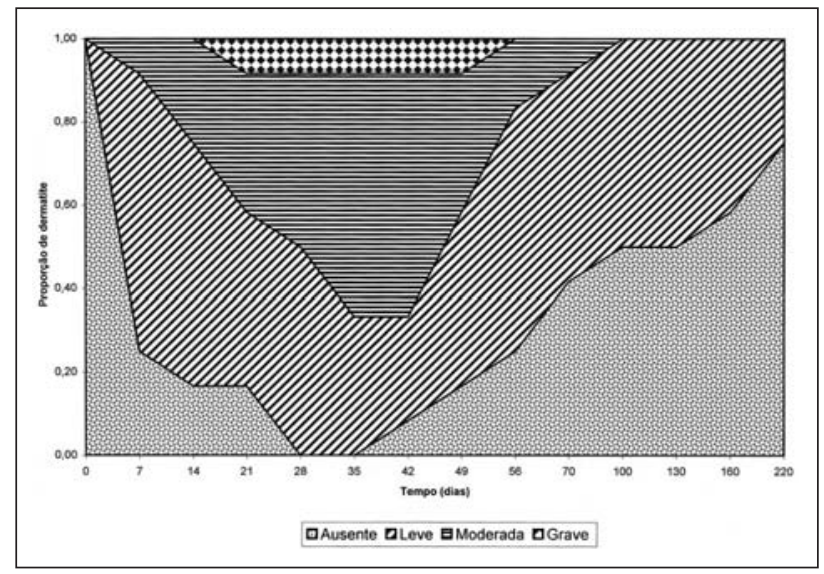

Figura 4. Representação gráfica da proporção de dermatite em função do tempo, em uma série de 12 pacientes com neoplasia na região de cabeça e pescoço que receberam RT. ( $T=0$ : início da RT; $t=49$ : término da RT; t > 49: início do acompanhamento após o término da RT).

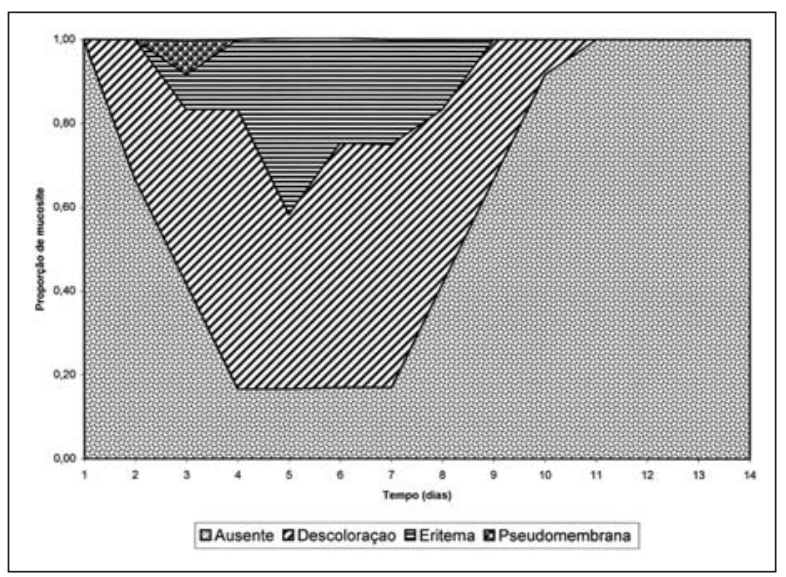

Figura 5. Representação gráfica da proporção de graus de mucosite em função do tempo, em uma série de 12 pacientes com neoplasia na região de cabeça e pescoço que receberam RT. ( $T=0$ : início da RT; $t=49$ : término da RT; t > 49: início do acompanhamento após o término da RT).

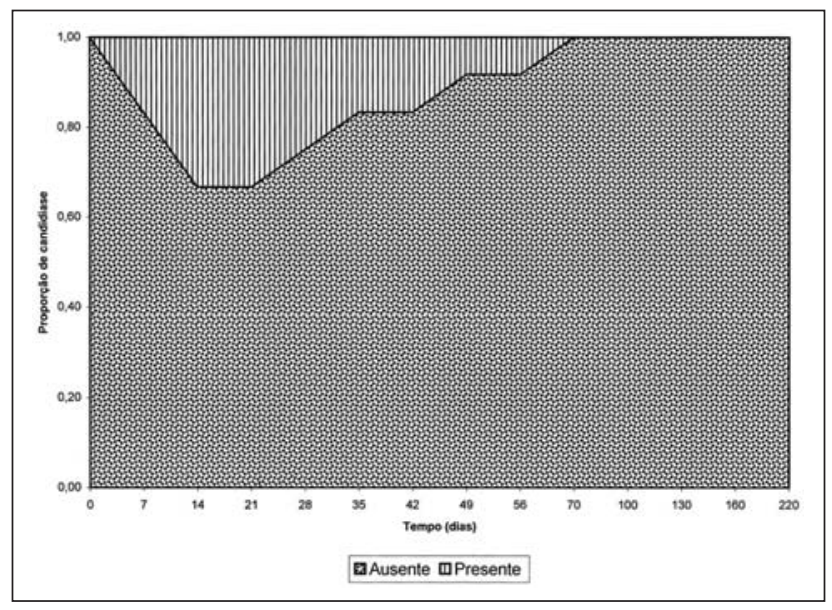

Figura 7. Representação gráfica da proporção de candidíase em função do tempo, em uma série de 12 pacientes com neoplasia da região de cabeça e pescoço que receberam $R T$. ( $T=0$ : início da $R T ; t=49$ : término da $R T ; t>49$ : início do acompanhamento após o término da RT).

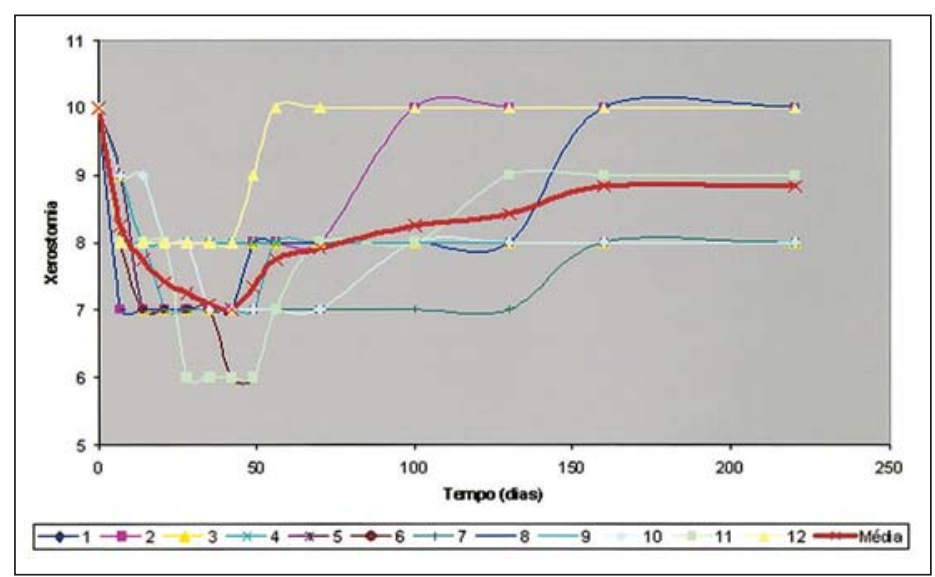

Figura 6. Representação gráfica da evolução de xerostomia em função do tempo, em uma série de 12 pacientes com neoplasia na região de cabeça e pescoço que receberam $\mathrm{RT}$. ( $\mathrm{T}=0$ : início da $\mathrm{RT} ; \mathrm{t}=49$ : término da $\mathrm{RT}$; $\mathrm{t}>$ 49: início do acompanhamento após o término da RT).

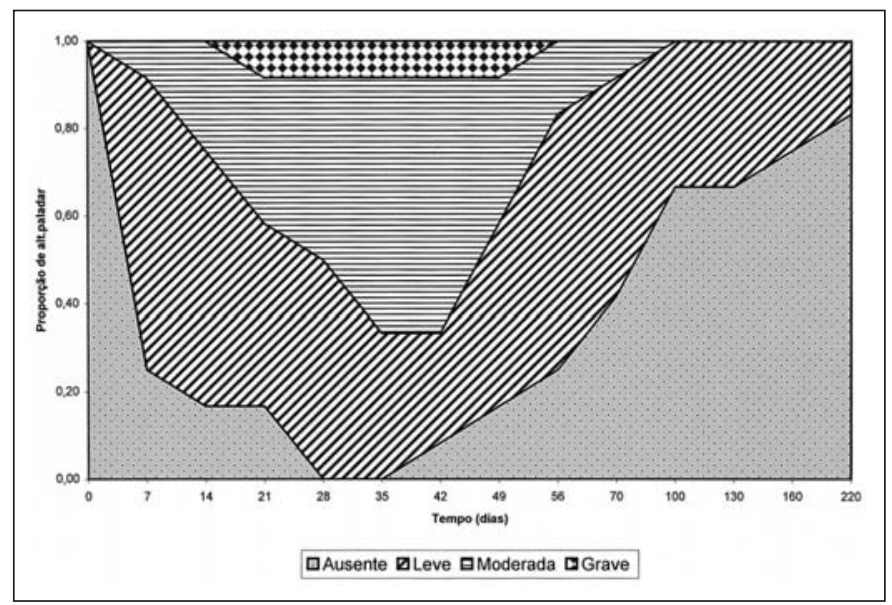

Figura 8. Representação gráfica da proporção de alteração de paladar em função do tempo, em uma série de 12 pacientes com neoplasia na região de cabeça e pescoço que receberam RT. ( $\mathrm{T}=0$ : início da RT; $\mathrm{t}=49$ : término da RT; $\mathrm{t}>$ 49: início do acompanhamento após o término da RT). 


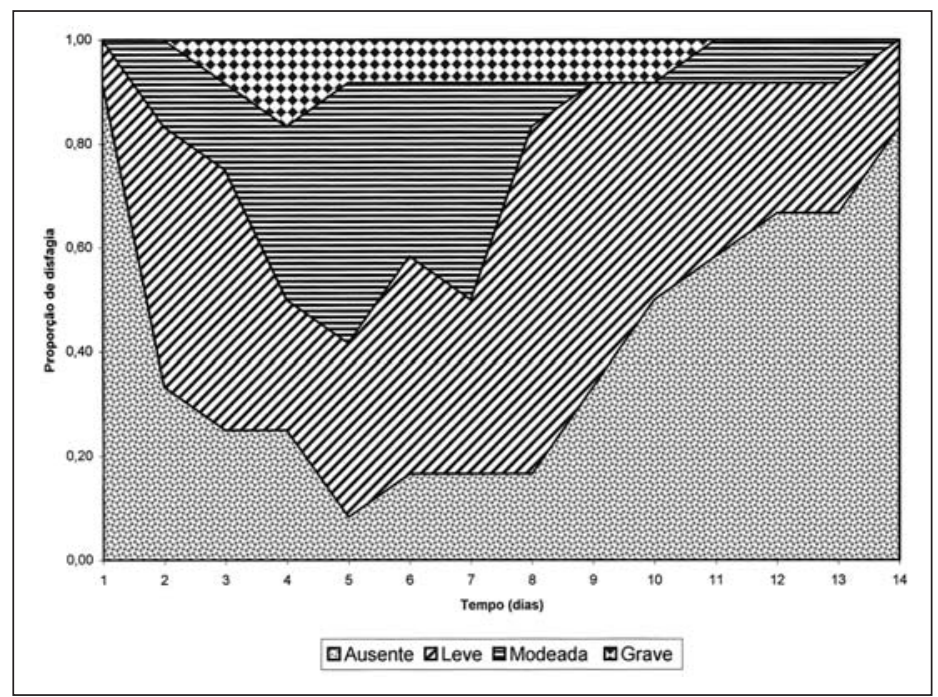

Figura 9. Representação gráfica da proporção de ocorrência de disfagia em função do tempo, em uma série de 12 pacientes com neoplasia na região de cabeça e pescoço que receberam RT. (T = 0: início da RT; $\mathrm{t}$ = 49: término da RT; $\mathrm{t}>$ 49: início do acompanhamento após o término da RT).

Tencarte et al. observam, em seu trabalho, que as alterações dérmicas se iniciam a partir da segunda semana. Em seus resultados, dos 18 pacientes estudados, somente quatro apresentaram radiodermite como efeito secundário ao tratamento ${ }^{(5)}$.

A mucosa, assim como a pele, apresenta-se com alta taxa de renovação celular, portanto, um tecido de resposta rápida. A reação aguda ocorre na mucosa devido à morte das células precursoras. Essas que deveriam substituir aquelas perdidas da mucosa deixam de fazê-lo por algum tempo, em função da dose de radiação recebida. Posteriormente, as células precursoras sobreviventes irão proliferar-se, reparando, assim, a mucosa ${ }^{(11,18)}$.

O nível e a duração da mucosite em pacientes tratados com RT estão relacionados com a dose acumulada, a intensidade, o volume da mucosa, o hábito de fumar, o consumo de álcool e outros fatores predisponentes, como xerostomia e infecção. Em programas preconizados de $200 \mathrm{cGy}$, o eritema ocorre na primeira semana do tratamento; placas ou pseudomembranas têm pico na quarta/quinta semanas da terapia. Com fracionamentos inferiores a $200 \mathrm{cGy}$, os graus são menos graves.

Existem diversos fatores de risco individual para o desenvolvimento da mucosite oral, como defeito enzimático, mecanismos de reparação do DNA, deficiência de ácido fólico e outros. Em pacientes imuno- competentes, em geral, em três semanas após o término da RT já não se verifica a presença de mucosite.

Em revisão de literatura realizada por Kostler et al., oferecendo opções para prevenção e tratamento, os autores referem que, a despeito do enorme arsenal disponível, a terapêutica tem-se mostrado com características de suporte e paliativa, aliviando sintomas e evitando complicações outras, como desidratação, caquexia e infecções ${ }^{(17)}$. Dentre as possibilidades citadas, temos a higiene oral, as aplicações de "soft laser", uma sucessão de drogas sendo avaliadas, mais recentemente as substâncias citoprotetoras, como a amifostina, entre outras. O efeito positivo dos cuidados intensivos da equipe envolvida no tratamento para o sucesso da terapêutica instituída não pode ser ignorado.

Em nosso estudo a mucosite ocorreu na totalidade dos pacientes, a partir da segunda semana de tratamento, atingindo uma proporção maior de descoloração entre a quarta e sexta semanas e de eritema entre a terceira e sétima semanas. Uma semana após o término temos $75 \%$ de ausência para 25\% de descoloração. Cabe lembrar que houve somente um caso de presença de pseudomembrana e nenhuma ocorrência de ulceração profunda, situação que é apontada, por alguns autores, como motivo de interrupção temporária da $\mathrm{RT}^{(6,13,19)}$. $\mathrm{O}$ fato de conseguirmos a obtenção de mucosite branda pode estar relacionado à aplicação de medidas preventivas de adequação bucal antes do início do tratamento, bem como a manutenção dessas medidas durante o período de vigência da RT.

A utilização dos bochechos com chá de camomila, apesar de não encontrarmos citações na literatura que comprovem a sua eficácia, pelos resultados obtidos, podemos inferir que teve participação importante quanto ao grau e ao alívio dos sintomas da mucosite, fato que pode estar associado à ação antiinflamatória da referida substância ${ }^{(17)}$.

A radiação induz à hipossalivação nos casos em que as glândulas salivares estão incluídas no campo de irradiaçãoo ${ }^{(14,20,21)}$. A duração da alteração é extremamente variável de paciente para paciente, e depende da dose, do campo e das diferenças biológicas individuais ${ }^{(20)}$.

Devido à perda dos ácinos secretores há uma diminuição da secreção de saliva em $80 \%$ dos pacientes que receberam doses de 40 cGy a 60 cGy; com doses acima de 60 cGy verifica-se a ocorrência na totalidade dos pacientes ${ }^{(11)}$.

A xerostomia teve sua presença em todos os pacientes durante todo o período do desenvolvimento deste trabalho, impondose a partir da segunda semana, quando foi possível observar uma queda de $17,5 \%$, em média. A partir daí continuou decrescendo, até 30\%, menor média obtida em relação ao valor inicial, considerado como $100 \%$. Na sexta semana após o término do tratamento observamos aumento gradativo, até recuperação de $88,3 \%$, em média.

No nosso estudo os constantes bochechos com água bicarbonatada e chá de camomila parecem ter contribuído para minimizar o desconforto da hipossalivação.

Ainda com relação à xerostomia, em nossa experiência clínica temos observado ser esta a alteração que mais incomoda o paciente na fase tardia de acompanhamento. Inicialmente utilizávamos saliva artificial, mas como o resultado por eles referido não foi satisfatório, optamos por não usá-la neste protocolo. A principal queixa era quanto à ação propriamente dita, pois continuavam sentindo desconforto ao falar, ao engolir, bem como em relação à manutenção da adesividade quanto ao uso da prótese total. O sabor é outra observa- 
ção apontada por eles como indicativo para a não utilização da saliva artificial. Eles preferiam carregar consigo uma garrafa de água, para fazer uso quando necessário, a utilizar-se da saliva artificial. Nesse sentido, Ord e Blanchaert ${ }^{(\mathbf{4})}$ fazem menção, em seu artigo, que vem ao encontro dos nossos achados.

Há um aumento da colonização por Candida albicans em pacientes submetidos à terapia por radiação na região de cabeça e pescoço, e a hipossalivação deve ser o maior fator predisponente ${ }^{(\mathbf{2 1})}$.

A C. albicans pode ter seu crescimento associado a estados de baixa resistência do hospedeiro, doenças debilitantes e à própria exposição à radiação ${ }^{(22,23)}$.

Em nosso estudo, cinco dos 12 pacientes apresentaram candidíase clínica. Em todos eles houve coincidência do fato de estarem na fase de maior grau de xerostomia, com redução de $30 \%$ do valor atribuído inicialmente. $\mathrm{O}$ paciente 2 encontravase com índice de $70 \%$, segundo a escala de Karnofsky; o mesmo ocorreu com o paciente 3; o paciente 5 apresentava índice de $80 \%$, que foi o seu mais baixo, durante todo o acompanhamento; o paciente 8 apresentava índices de $70 \%$ a $80 \%$ e o paciente 9 , índice de $80 \%$. Somente o paciente 9 voltou a apresentar candidíase após o término da RT. Cabe lembrar que em nenhum paciente foram observadas extensas áreas de comprometimento.

Nossos achados apresentam ocorrência de candidíase clínica de 41,6\%. Estudos realizados por diferentes autores, durante a vigência de terapia por radiação, envolvendo pacientes irradiados na região de cabeça e pescoço, demonstram a presença de valores de $11,8 \%, 17,4 \%$ e $27 \%{ }^{(\mathbf{5 , 2 1 , 2 4})}$. Cabe lembrar que a patogenia da infecção por Candida é bastante complexa, envolvendo ambos, fungo e hospedeiro. A colonização parece ser influenciada por mecanismos de aderência entre o fungo e as células do epitélio da mucosa. As manifestações clínicas dependem do crescimento da levedura, que, provavelmente, está na dependência de fatores como reflexos das proteínas expressas pela Candida, matriz extracelular das células do hospedeiro, possibilidade de congregação entre o fungo e a bactéria, bem como a imunocompetência do paciente ${ }^{(\mathbf{2 1}, \mathbf{2 5})}$.
As células gustativas estão sempre sendo substituídas, através de divisões mitóticas das células epiteliais vizinhas. Assim, pode-se observar, em pouco tempo, grande capacidade de repopulação das células gustativas, após sofrerem irradiação ${ }^{(\mathbf{1 3 )}}$.

As alterações do paladar ocorreram em todos os pacientes em diferentes graus, atingindo a proporção máxima por volta da sexta semana. Com o término do tratamento, progressivamente houve a recuperação das papilas gustativas irradiadas. Ao final dos 180 dias de acompanhamento, a proporção de ausência foi de $83 \%$. O fato de ainda encontrarmos um pouco de alteração de paladar 180 dias após o término de tratamento pode estar relacionado à presença de xerostomia ${ }^{(11)}$.

A disfagia, quando prontamente identificada e avaliada, permite reabilitação mais rápida e efetiva, possibilitando o restabelecimento do estado nutricional do paciente e sua possível reintegração social ${ }^{(\mathbf{2 6})}$.

A xerostomia pode causar dificuldades no ato de engolir, afetando o conforto na ingestão dos alimentos ${ }^{(4)}$.

No presente estudo a disfagia foi relatada por 11 dos 12 pacientes acompanhados, sendo que somente em dois houve gravidade que exigiu a colocação de sonda nasogástrica. Os demais exibiram as formas moderada e leve.

A placa bacteriana é o agente etiológico infeccioso da cárie dental e da doença periodontal. Essa placa é constituída por massa amolecida de material orgânico gelatinoso, formada a partir da saliva, que contém, essencialmente, mucopolissacarídios salivares que se aderem à superfície dos dentes e gengivas, onde vão incorporando microorganismos. As placas responsáveis pelas cáries são constituídas por Streptococcus mutans e Lactobacillus ${ }^{(\mathbf{2 7})}$.

Considera-se a cárie como doença crônica, pois sua evolução é variável, podendo ser de meses ou anos. O tempo médio de estágio de uma cárie incipiente até uma cárie clínica é de 18 meses \pm 6 meses, levando-se em consideração uma escovação normal, exceção feita às crianças, cujo intervalo pode variar de três a 18 meses. Há de se ressaltar ainda que, em pacientes com xerostomia e submetidos à RT, pode haver detecção clínica em três meses ${ }^{(\mathbf{2 8})}$. A terapia por irradiação incluindo as glândulas salivares maiores resulta em hipossalivação ou xerostomia e, como consequiência, um aumento no número de cáries ${ }^{(13,29,30)}$.

A xerostomia causa efeitos drásticos sobre a dentição, resultando em cáries e hipersensibilidade. Em virtude de uma rápida progressão da cárie de irradiação, o acompanhamento sistemático se faz necessário, bem como a aplicação de medidas preventivas para reduzir a incidência de complicações. Muitos pacientes acabam procurando o tratamento quando as complicações já estão instaladas ${ }^{(8)}$.

A cárie dental, em sua formação multifatorial, requer um esquema preventivo abrangente que inclui: exame clínico minucioso, para diagnosticar lesões incipientes ${ }^{(\mathbf{3 1}, 32)}$; avaliação radiográfica, constando de RX periapical e ortopantomografia; profilaxia dental, para remoção da placa bacteriana e tártaros; ensinamentos de técnicas de higienização, que deverão ser incorporados ao dia-a-dia do paciente, escovação, uso do fio dental; aplicação tópica

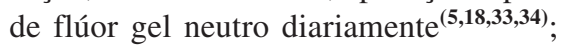
estimulação do fluxo salivar; bem como orientações sobre a dieta, pois os pacientes com hipossalivação tendem a mudar a dieta para uma mais pastosa e com muito açúcar ${ }^{(\mathbf{1 4}, 30)}$. Essas medidas preventivas devem estar associadas a um monitoramento sistemático $^{(8)}$.

Em nossos resultados não observamos a presença de cáries, indicando que os procedimentos utilizados, tratamento das lesões, orientações gerais, higienização, aplicação tópica de flúor, desde o período que antecedeu a RT e que são reforçados e

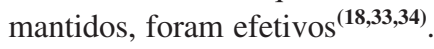

O tecido muscular é considerado tecido de resposta lenta, apresentando, portanto, alterações por tempo mais prolongado após a irradiação ${ }^{(11)}$. Assim, o fato de não termos encontrado a presença de trismo em nossos resultados pode estar relacionado com um período de acompanhamento insuficiente para a ocorrência.

Por outro lado, não podemos deixar de salientar que os exercícios realizados podem estar contribuindo para o resultado, uma vez que promovem o relaxamento da musculatura, treinamento da função muscular rítmica e coordenada, aumento da amplitude de movimentos e também da força muscular ${ }^{(35,36)}$. 
A osteorradionecrose pode ser prevenida com medidas adequadas de higiene oral, avaliação e tratamento odontológico prévio, para remoção de cáries, raspagem de tártaros, eliminação dos elementos dentais com cáries extensas ou com periodontopatias, orientação e preparo do paciente para os possíveis efeitos do tratamento por irradiação ${ }^{(4,7,18,37-39)}$.

O tempo de espera entre o procedimento cirúrgico para remoção dos elementos dentais comprometidos e o início da radioterapia deve ser o necessário para que se permita o reparo inicial, estimado entre sete e 14 dias $^{(33,40)}$, e as exodontias realizadas com um mínimo de trauma às estruturas, com alveoloplastia criteriosa ${ }^{(41)}$.

A proteção dos dentes remanescentes mediante aplicação tópica de flúor figura como um cuidado essencial para se evitar

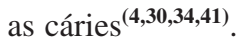

O desencorajamento em relação ao uso de próteses dentárias parciais removíveis/ totais durante o curso da terapia por irradiação se faz necessário. As próteses deverão ser rigorosamente observadas quando da recolocação, para evitar a possibilidade de trauma sobre as estruturas de suporte. Se preciso, ajustes poderão ser feitos ou até mesmo a substituição em deter-

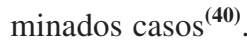

Deve-se evitar a exodontia após o curso da irradiação ${ }^{(\mathbf{8 , 4 0})}$. Em caso de pulpite, o dente deverá receber tratamento endodôntico, tomando-se o cuidado de não introduzir microorganismos pela instrumentação ${ }^{(33)}$. Quando houver necessidade extrema de remoção de elemento dental, se possível utilizar técnica incruenta, em que a avulsão se dá através da reabsorção óssea periodontal. Elásticos ortodônticos são introduzidos no sulco gengival, provocando inflamação, com migração da aderência apical e reabsorção óssea horizontal, culminando com mobilidade e avulsão ${ }^{(\mathbf{1 2})}$; ou ainda, quando as técnicas acima descritas não forem possíveis, a exodontia convencional precedida de oxigenação hiperbárica e a manutenção da oxigenação por um período após o término do procedimento é uma possibilidade. Essa também é a conduta que pode ser considerada para a prevenção de osteorradionecrose, quando da necessidade de pequenas cirurgias e grandes reconstruções faciais ${ }^{(\mathbf{4 , 6}, \mathbf{4 2})}$.
O não aparecimento de osteorradionecrose em nosso estudo já era esperado, visto que os principais fatores predisponentes $\mathbf{s}^{(\mathbf{8}, \mathbf{3 3}, 40,41)}$ foram bem controlados. Apesar de tratar-se de um efeito tardio e nosso período de acompanhamento ter completado apenas seis meses, há relatos na literatura cuja variação vai desde 3-7 meses até 38-45 anos ${ }^{(\mathbf{4 3})}$. Entendemos e concordamos com Marx quando este refere que após a irradiação o tecido torna-se hipóxico, hipovascular e hipocelular, fatores que agem impedindo a reestruturação do osso, podendo permanecer nessa condição por tempo indeterminado ${ }^{(\mathbf{4 4 , 4 5})}$.

Existem dois picos importantes em que há maior incidência de osteorradionecrose induzida: o primeiro durante o primeiro ano, e o segundo entre o segundo e quinto ano após a RT. As cirurgias oncológicas são responsáveis pela ocorrência de aproximadamente $50 \%$ dos fatores desencadeantes no primeiro pico; já no segundo período, mais de $60 \%$ são devidos a procedimentos odontológicos ${ }^{(\mathbf{4 0})}$.

No período durante a RT os pacientes apresentaram queda no estado geral, mais visível quando próximo do final das aplicações. As ocorrências de mucosite, xerostomia, alteração do paladar, falta de apetite, disfagia, infecções oportunistas, concorrem para a debilitação do paciente e diminuição de sua qualidade de vida. Com o término do tratamento e a crescente remissão desses fatores, verificamos melhora considerável no estado geral, chegando a atingir média de $90 \%$ ao final de 180 dias.

Diante dos nossos resultados podemos inferir que, prevenindo e controlando as seqüelas induzidas pela ação da irradiação no tratamento de neoplasias da região de cabeça e pescoço, estaremos também possibilitando melhoria na qualidade de vida desses pacientes.

\section{CONCLUSÃO}

A instituição de um protocolo odontológico para o acompanhamento dos pacientes irradiados na região de cabeça e pescoço, dividido em fases, nos faculta observar as possíveis alterações no decorrer do tratamento e após este, nos oferecendo a oportunidade de prevenção e tratamento. A importância dos cuidados dispensa- dos durante esse período reforça a idéia de que se faz necessária uma relação multidisciplinar, envolvendo o dentista trabalhando juntamente com a equipe médica e outros profissionais da saúde, com a finalidade de promover melhores condições de restabelecimento desses pacientes, focando não só a remissão do tumor propriamente dita, mas também a sua reintegração no meio familiar e social, proporcionandolhes, assim, melhor qualidade de vida.

\section{REFERÊNCIAS}

1. Sherman CD. Câncer de cabeça e pescoço. In: Hossfeld DK, Sherman CD, Love RR, Bosch F, eds. Manual de oncologia clínica. 5a ed. São Paulo, SP: Fundação Oncocentro de São Paulo, 1996:193-7.

2. Instituto Nacional de Câncer. Estimativa da incidência e mortalidade por câncer no Brasil. (Citado 2002, nov 30). Disponível em: URL: http://www. inca.gov.br

3. Tabakof J. Quimioterapia. In: Parisi Jr O, ed. Câncer de boca. Aspectos básicos e terapêuticos. $1^{\mathrm{a}} \mathrm{ed}$. São Paulo, SP: Sarvier, 2000:173-8.

4. Ord RA, Blanchaert RH Jr. Current management of oral cancer. A multidisciplinary approach. J Am Dent Assoc 2001;132:19S-23S.

5. Tencarte CR, Froio GL, Machado ML, Biazolla ER. Tratamento dos efeitos secundários da actinoterapia na esfera bucal. Conduta do Centro de Oncologia Bucal. Rev Bras Odontol 1997;54:146-8.

6. Dib LL, Cury MM. Complicações orais na oncologia. In: Salvajoli JV, Souhami L, Faria SL, eds. Radioterapia em oncologia. Rio de Janeiro, RJ: Medsi, 1999:1146-57.

7. Magalhães MG. Enfrentando o câncer bucal. Rev Assoc Paul Cir Dent 1999;53:353-60.

8. De Moor R. Influence directe and indirecte de la médication (chimiotérapie y comprise) et de I'irradiation sur la pulpe. Rev Belge Med Dent 2000;55: 321-33.

9. Lima AAS, Figueiredo MAZ, Loureiro MS, Duarte R. Radioterapia de neoplasias malignas na região de cabeça e pescoço - o que o cirurgião dentista precisa saber. Revista Odontociência 2001;16: 156-63.

10. Segreto RA, Segreto HRC. Radioterapia. In: Ramos OL, Rothschild HA, eds. Atualização terapêutica. 19a ed. São Paulo, SP: Artes Médicas, 1999: 1370-2.

11. Segreto HRC, Segreto RA. Revisão e atualização em radiobiologia. Aspectos celulares, moleculares e clínicos. Folha Med 2000;119:9-27.

12. Boraks S. Diagnóstico bucal. 2 $2^{\mathrm{a}}$ ed. São Paulo, SP: Editora Artes Médicas, 1999:347-97.

13. Abreu CEV, Silva JLF. Teleterapia. In: Parisi Jr O, ed. Câncer de boca. Aspectos básicos e terapêuticos. 1ª ed. São Paulo, SP: Sarvier, 2000:153-9.

14. Dib LL, Gonçalves RCC, Kowalski LP, Salvajoli JV. Abordagem multidisciplinar das complicações orais da radioterapia. Rev Paul Cir Dent 2000;54: 391-6.

15. Henson BS, Inglehart MR, Eisbruch A, Ship JA. Preserved salivary output and xerostomia-related quality of life in head and neck cancer patients receiving parotid-sparing radiotherapy. Oral Oncol 2001;37:84-93. 
16. Schag CC, Heinrich RL, Ganz PA. Karnofsky performance status revisited: reliability, validity, and guidelines. J Clin Oncol 1984;2:187-93.

17. Köstler WJ, Hejna M, Wenzel C, Zielinski CC. Oral mucositis complicating chemotherapy and/or radiotherapy: options for prevention and treatment. CA Cancer J Clin 2001;51:290-315.

18. Caielli C, Martha PM, Dib LL. Seqüelas orais da radioterapia: atuação da odontologia na prevenção e tratamento. Rev Bras Cancerol 1995;41:231-41.

19. Freire RCCG, Kowalski LP, Dib LL, Ribeiro KCB. Risk factors for severe oral mucositis induced by radiotherapy. Proceedings of the 1st Congress of Head and Neck Oncology, Madrid, Spain. Bologna, Italy: Monduzzi Editore, 1988:881-4.

20. Silverman S Jr, Chierici G. Radiation therapy of oral carcinoma. I. Effects on oral tissues and management of the periodontium. J Periodontol 1965;36: 478-84.

21. Ramirez-Amador V, Silverman S Jr, Mayer P, Tyler M, Quivey J. Candidal colonization and oral candidiasis in patients undergoing oral and pharyngeal radiation therapy. Oral Surg Oral Med Oral Pathol Oral Radiol Endod 1997;84:149-53.

22. Shafer WG. Lesões físicas e químicas da cavidade bucal. In: Shafer WG, Hine MK, Levy BM, eds. Patologia bucal. $2^{\mathrm{a}}$ ed. Rio de Janeiro, RJ: Editora Interamericana, 1985:486-548.

23. Silverman S Jr. Diagnosis and management of leukoplakia and premalignant lesions. Oral Maxillofac Surg Clin North Am 1998;10:13-23.

24. Redding SW, Zellars RC, Kirkpatrick WR, et al Epidemiology of oropharyngeal Candida colonization and infection in patients receiving radiation for head and neck cancer. J Clin Microbiol 1999;37: 3896-900.

25. Schuster GS. Doenças virais com manifestações bucais. In: Topaziam RG, Goldberg MH, eds. Infecções maxilofaciais e orais. 3 a ed. São Paulo, SP: Santos Livraria Editora, 1987:594-6.
26. De Angelis EC. Fonoaudiologia na reabilitação do câncer de boca. In: Parisi Jr O, ed. Câncer de boca. Aspectos básicos e terapêuticos. 1ํㅡㄹ. ed. São Paulo, SP: Sarvier, 2000:245-52.

27. Basraani E, De Boces EP. Etiopatogenia das alterações pulpares. In: Paiva JG, Antoniazzi JH, eds. Endodontia. Bases para a prática clínica. 2 a ed. São Paulo, SP: Artes Médicas, 1988:37-76.

28. Maciel SM, Chedid RR, Guedes-Pinto AC. Cárie dentária. In: Guedes-Pinto AC, ed. Odontopediatria. $2^{a}$ ed. São Paulo, SP: Santos Livraria Editora, 1990:353-95.

29. Silveira E, Guidi D. Etiopatogenia da cárie dental. In: Correa AA, ed. Dentística operatória. São Paulo, SP: Artes Médicas, 1979:63-75.

30. Giertsen E, Scheie AA. In vivo effects of fluoride, chlorhexidine and zinc ions on acid formation by dental plaque and salivary mutans Streptococcus counts in patients with irradiation-induced xerostomia. Eur J Cancer B Oral Oncol 1993;29B:30712.

31. Maciel SM, Chedid RR, Guedes-Pinto AC. Cárie dentária. In: Guedes-Pinto AC, ed. Odontopediatria. $2^{\underline{a}}$ ed. São Paulo, SP: Santos Livraria Editora, 1990:353-95.

32. Grutz KA, Riesenbeck D, Brahm R, et al. Chronic radiation effects on dental hard tissue (radiation caries). Classification and therapeutic strategies. Strahlenther Onkol 2001;177:96-104.

33. Topaziam RG, Goldberg MH. Infecções maxilofaciais e orais. 3a ed. São Paulo, SP: Santos Livraria Editora, 1997:279-85.

34. Rudat V, Meyer J, Momm F, et al. Protective effect of amifostine on dental health after radiotherapy of the head and neck. Int J Radiat Oncol Biol Phys 2000;48:1339-43.

35. Ochs MW, Dolwick MF. As lesões condilares e suas seqüelas. In: Zarb GA, Carlsson GE, Sessle BJ, Mohl ND, eds. Disfunção da articulação temporomandibular e dos músculos da mastigação. $2^{\underline{a}}$ ed.
São Paulo, SP: Santos Livraria Editora, 2000:31543.

36. Zarb GA, Carlsson GE, Rugh JD. Controle clínico. In: Zarb GA, Carlsson GE, Sessle BJ, Mohl ND, eds. Disfunção da articulação temporomandibular e dos músculos da mastigação. 2 $2^{\mathrm{a}}$ ed. São Paulo, SP: Santos Livraria Editora, 2000:529-48.

37. Migliorati CA, Migliorati EKJ. Preparo odontológico. In: Parisi Jr O, ed. Câncer de boca. Aspectos básicos e terapêuticos. $1^{\mathrm{a}}$ ed. São Paulo, SP: Sarvier, 2000:185-92.

38. Bueno YC, Carvalho MB. Osteorradionecrose de mandíbula em pacientes com câncer de boca. Rev Bras Med Otorrinolaringol 1997;4:169-74.

39. Schiodt M, Hermund NU. Management of oral disease prior to radiation therapy. Support Care Cancer 2002;10:40-3.

40. Miguel REV, Curi MM. Osteorradionecrose e oxigenação hiperbárica. In: Parisi Jr O, ed. Câncer de boca. Aspectos básicos e terapêuticos. São Paulo, SP: Sarvier, 2000:212-9.

41. Epstein JB, Rea G, Wong FLW, Spinelli J, Stevenson-Moore P. Osteonecrosis: study of the relationship of dental extractions in patients receiving radiotherapy. Head Neck Surg 1987;10:48-54.

42. Hasson O, Nahliel O. Oxigênio hiperbárico e sua aplicação no tratamento da osteorradionecrose e da osteomielite. Rev Assoc Paul Cir Dent 1999;53: 379-82.

43. Soares HA, Marcucci G. Osteorradionecrose: avaliação dos fatores de risco. Rev Odontol Univ São Paulo 1996;10:9-14.

44. Mirante JP, Urken ML, Aviv JE, Brandwein M, Buchbinder D, Biller HF. Resistance to osteoradionecrosis in neovascularized bone. Laryngoscope 1993; 103:1168-73.

45. Marx RE. Osteoradionecrosis: a new concept of its pathophysiology. J Oral Maxillofac Surg 1983;41: 283-8. 